\title{
TO MEASURE QUALITY OF SPIROMETRY IN BIHAR
}

\author{
Deependra Kumar Rai1, Abhishek Kumar², Shyama Kumari³, Somesh Thakur ${ }^{4}$, Asish Ansuman 5 \\ ${ }^{1}$ Assistant Professor and HOD, Department of Pulmonary Medicine, All India Institute of Medical Sciences, Phulwari Sharif, Patna. \\ ${ }^{2}$ Senior Resident, Department of Pulmonary Medicine, All India Institute of Medical Sciences, Phulwari Sharif, Patna. \\ 3 Postgraduate Student, Department of Kaya Chikitsa, Dayanand Ayurvedic College, Siwan. \\ ${ }^{4}$ Assistant Professor, Department of Pulmonary Medicine, All India Institute of Medical Sciences, Phulwari Sharif, Patna. \\ 5Junior Resident, Department of Pulmonary Medicine, All India Institute of Medical Sciences, Phulwari Sharif, Patna.
}

ABSTRACT
BACKGROUND
Spirometry is a physiological test that measures how an individual inhales or exhales volume of air as a function of time. The
increased availability of spirometry in primary care is a welcome step, as it provide rapid access to diagnosis and monitoring nearby
to the patient's home. A poorly performed test and misinterpretation of the result can lead to misdiagnosis and inappropriate
management, potentially bringing patients at risk. The basic purpose of the study is to identify quality of spirometry practices in
Bihar.

\section{MATERIAL AND METHOD}

This was a hospital-based cross-sectional study. We assessed 207 spirogram done out of institute for quality of spirometry which include flow volume curve, number of manoeuvre, etc. We also assessed awareness about spirometry technique in 10 technicians.

\section{RESULTS}

A total of 207 patients with spirogram enrolled for study between July 2015 and Sep 2015 . This study shows that only $14 \%$ spirograms were acceptable. The spirograms were reproducible only in $51.69 \%$. The reversibility testing was performed in only $16.90 \%$ and so only $32.11 \%$ of obstructive spirogram underwent for reversibility testing. The most common error found in flow volume curve was blunt peak (50.96\%) followed by notch in early part (30.76), variable effort (30.76), delayed peak (16.34) and poor start (11.53). Many technicians were not aware about the acceptability criteria, number of attempts or indication of reversibility.

\section{CONCLUSION}

Spirometry is effort-dependent test and the role of the person doing the test is a guide for the person who interprets spirogram and correlates clinically and should not underestimate. Training and regular practice is vital.

\section{KEYWORDS}

Spirometry, Acceptability, Reproducibility, Awareness.

HOW TO CITE THIS ARTICLE: Rai DK, Kumar A, Kumari S, et al. To measure quality of spirometry in Bihar. J. Evolution Med. Dent. Sci. 2016;5(79):5915-5918, DOI: 10.14260/jemds/2016/1335

\section{BACKGROUND}

Spirometry is a physiological test that measures how an individual inhales or exhales volume of air as a function of time. The primary parameter measured in spirometry can be volume or flow. It is recommended for the diagnosis and management of asthma and COPD in national and international guidelines, and specialist respiratory societies such as the American Thoracic and European Respiratory Societies (ATS/ERS) have published guidelines on standards of spirometry. ${ }^{1}$ There are also specific guidelines for diagnosis of the numerous respiratory diseases presenting in primary care. The increased availability of spirometry in primary care is a welcome step, since it provide rapid access to diagnosis and monitoring close to the patient's home. A poorly performed

Financial or Other, Competing Interest: None.

Submission 26-08-2016, Peer Review 20-09-2016,

Acceptance 26-09-2016, Published 03-10-2016.

Corresponding Author:

Dr. Deependra Kumar Rai,

Assistant Professor \& HOD,

Department of Pulmonary Medicine,

All India Institute of Medical Sciences,

Phulwari Sharif, Patna-801105.

E-mail: deependra78@gmail.com

DOI: $10.14260 /$ jemds $/ 2016 / 1335$ test and misinterpretation of the results can lead to misdiagnosis and inappropriate management, potentially bringing patients at risk. Spirometry can be performed on different types of equipment and requires cooperation between the subject and the examiner and the result obtained will depend on technical as well as personal factors. Spirometry is effort-dependent and the role of the person administering the test as 'coach' to the patient cannot be underestimated. Training and regular practice is vital. Equally, the result of spirometry testing needs to be properly interpreted in the light of the clinical history and presentation - ideally at the time of testing.

The Joint ICS/NCCP (India) recommends spirometry in all patients suspected of having COPD. ${ }^{2}$ In the absence of availability of spirometry, patients suspected of having COPD should be referred for spirometric evaluation to a centre with this facility. ${ }^{3}$

Diagnosis of any disease requires a complex series of decisions based on clinical history, examination and investigations. Accurate spirometry is an essential part of clinical practice in primary care and management ${ }^{2}$ as well as monitoring of COPD and asthma. 4,5

Barriers to spirometry use in general practice include lack of expertise in performing spirometry, Poor access to a wellmaintained spirometers, Time consuming nature of pre- and 
post-BD spirometry, Low confidence in spirometry interpretation. Therefore, it is essential that those performing spirometry should be trained and able to demonstrate their competence to do the test, identify errors and interpret the results at the point of contact. There are no studies on quality of spirometry and awareness about spirometry interpretation in Physician and Technician. The basic purpose of the study to identify quality of spirometry practices in Bihar.

\section{OBJECTIVE}

1. To measure accuracy of spirometry performed in Bihar.

2. Awareness about spirometry technique in technician.

\section{MATERIAL AND METHOD}

\section{Design of Study}

Hospital-based cross-sectional study.

\section{Data Collection}

We have selected all patients coming to AIIMS Pulmonary Medicine, OPD, who underwent spirometry for lung function irrespective of disease. We assessed 207 spirograms, which was done outside this institute. The factors that are considered during evaluation and interpretation of spirometry such as personal profile such as age, sex, height, flow volume curve, number of manoeuvre, weight, BMI and smoking status.

The awareness about spirometry among technician is accessed by predefined questionnaire related to spirometry procedure.

\section{DEFINITION}

We report Spirometry report as Acceptable, Suboptimal and Questionable (Unacceptable).

The measurements were analysed according to ATS guidelines.[4] Spirometry was considered normal if the FEV1/FVC ratio was higher than 0.70 and the FVC higher than $80 \%$ of predicted value. Obstruction was diagnosed in cases where the FEV1/FVC was lower than 0.70 . Its severity was classified according to the COPD severity grading by GOLD (Global Initiative for Chronic Obstructive Lung Disease). Obstruction was described as mild when the FEV1 $>80 \%$ of predicted value, moderate when it was $80-50 \%$ of predicted value, severe when $50-30 \%$ of predicted value and very severe when $<30 \%$ of predicted value. Restriction was suspected in cases where the FEV1/FVC was $>0.7$ and FVC was $<80 \%$ of predicted value.

\section{Acceptable Criteria}

Minimum of three acceptable and reproducible spirogram.

\section{Acceptable Spirogram Criteria}

Adequate inspiration before expiration, no hesitation at start no cough during early part of forced exhalation, satisfactory exhalation and exhalation time should be minimum of 6 seconds or unless there is no volume change for at least 1 second.

\section{Suboptimal}

Spirogram is acceptable but less than 3 acceptable spirogram or not reproducible.

\section{Unacceptable (Questionable)}

When spirogram is not acceptable and not reproducible.
Then we look for type of F-V abnormalities in Unacceptable (Questionable) spirogram such as Variable effort, Notch: A notch in initial part indicates a cough or hesitant start.

\section{Blunt Peak}

Indicates inadequate effort.

\section{Delayed Peak}

Sometime the curve starts from zero, but the peak is delayed. This pattern indicates defective start and the test should be repeated.

\section{Flat Peak}

Reduced flow rate along with expiratory plateau indicates intrathoracic obstruction.

\section{Reproducible Criteria}

Two largest FVC should be within $150 \mathrm{~mL}$ of each other and the two largest FEV1 should be within $150 \mathrm{~mL}$ of each other. For those with FVC of $<1.0 \mathrm{~L}$, both these values are $100 \mathrm{~mL}$. The study was approved by the Ethics and Research Committee of the All India Institute of Medical Sciences, Patna.

The awareness about spirometry among technician is also assessed by observing the technique and interview with fixed questionnaire such as how they are taking Weight/Height, Awareness about acceptability criteria, Satisfactory manoeuvre demonstration to the patients, Awareness regarding maximum number of attempts, Knowledge about infection control measures and Knowing contraindications of spirometry.

\section{Statistical Analysis}

\section{Outcome Variable}

1. Flow-volume curve.

Acceptable criteria.

Suboptimal: Unacceptable (Questionable)

2. Reproducible: Yes or No.

3. Bronchodilator reversibility test performed: Yes or No.

4. How many attempts taken for spirogram.

5. FET (Forced Expiratory Time).

\section{RESULT}

\begin{tabular}{|c|c|c|}
\hline Sl. No. & Age Group & No. of Patients \\
\hline 1. & $10-20$ & 16 \\
\hline 2. & $21-30$ & 23 \\
\hline 3. & $31-40$ & 23 \\
\hline 4. & $41-50$ & 14 \\
\hline 5. & $51-60$ & 15 \\
\hline 6. & $61-70$ & 15 \\
\hline 7. & $70+$ & 4 \\
\hline
\end{tabular}

\begin{tabular}{|c|c|c|c|c|}
\hline Sl. No. & Characteristics & $\begin{array}{c}\text { Total } \\
(\mathbf{n = 2 0 7})\end{array}$ & $\begin{array}{c}\mathbf{M} \\
(\mathbf{n = 1 1 9})\end{array}$ & $\begin{array}{c}\mathbf{F} \\
(\mathbf{n = 8 8})\end{array}$ \\
\hline 1. & Age & & 45.9 & 41.6 \\
\hline 2. & BMI & & 22.3 & 22.5 \\
\hline 5. & Interpretation & & & \\
\hline & Obstructive & $\begin{array}{c}109 \\
(52.65)\end{array}$ & 65 & 44 \\
\hline & Restrictive & $45(21.73)$ & 20 & 25 \\
\hline \multicolumn{4}{|c|}{ Table 1: Characteristic of Study Patients } \\
\hline
\end{tabular}




\begin{tabular}{|c|c|c|c|c|}
\hline $\begin{array}{ll}\text { Sl. } \\
\text { No. }\end{array}$ & Variables & $\begin{array}{c}\text { Total } \\
(\mathrm{n}=\mathbf{2 0 7})\end{array}$ & $\begin{array}{c}M \\
(n=119)\end{array}$ & $\begin{array}{c}F \\
(n=88)\end{array}$ \\
\hline 1. & FET $>6 s$ & $\begin{array}{c}144 \\
(69.56)\end{array}$ & 87 & 57 \\
\hline \multirow[t]{4}{*}{2.} & Spirometry & & & \\
\hline & Acceptable & $\begin{array}{c}29 \\
(14.00)\end{array}$ & 19 & 10 \\
\hline & Suboptimal & $\begin{array}{c}74 \\
(35.74) \\
\end{array}$ & 50 & 24 \\
\hline & $\begin{array}{l}\text { Unacceptable } \\
\text { (Questionable) }\end{array}$ & $\begin{array}{c}104 \\
(50.24)\end{array}$ & 53 & 51 \\
\hline 3. & Reproducible & $\begin{array}{c}107 \\
(51.69)\end{array}$ & 59 & 48 \\
\hline 4. & $\begin{array}{l}\text { Reversibility } \\
\text { Testing, Yes }\end{array}$ & $\begin{array}{c}35 \\
(16.90)\end{array}$ & 19 & 16 \\
\hline 5. & $\begin{array}{l}\text { Average number } \\
\text { of attempts }\end{array}$ & 3 & 2.91 & 3.1 \\
\hline 6. & $\begin{array}{l}\text { Average number } \\
\text { of acceptable } \\
\text { manoeuvre per } \\
\text { patient }\end{array}$ & 1.71 & 1.5 & 0.9 \\
\hline 7. & $\begin{array}{l}\text { At least three } \\
\text { acceptable } \\
\text { manoeuvres }\end{array}$ & $\begin{array}{c}38 \\
(18.35)\end{array}$ & 24 & 14 \\
\hline \multicolumn{5}{|c|}{$\begin{array}{c}\text { Table 2: The Most Frequent Errors in Spirometry } \\
\text { Performance and Interpretation }\end{array}$} \\
\hline
\end{tabular}

\begin{tabular}{|ll|c|c|}
\hline \multicolumn{1}{|c|}{ Error } & $\begin{array}{c}\text { Total } \\
(\mathbf{n = 1 0 4 )}\end{array}$ & Percentage \\
\hline 1. & FV curve not acceptable & 97 & 93.26 \\
\hline a. & Variable effort & 32 & 30.76 \\
\hline b. Notch in early part & 32 & 30.76 \\
\hline c. & Blunt peak & 53 & 50.96 \\
\hline d. Delayed peak & 17 & 16.34 \\
\hline e. False start (Hesitancy) & 12 & 11.53 \\
\hline 2. Not reproducible & 58 & 55.76 \\
\hline \multicolumn{3}{|c|}{ Table 3: Most Common Error in } \\
\hline \multicolumn{3}{|c|}{ Unacceptable Spirogram } \\
\hline
\end{tabular}

\begin{tabular}{|c|l|c|c|}
\hline & \multicolumn{1}{|c|}{ Errors } & $\begin{array}{c}\text { Total } \\
(\mathbf{n = 1 0})\end{array}$ & Percentage \\
\hline 1. & Measure actual weight/Ht & 8 & 80 \\
\hline 2. & $\begin{array}{l}\text { Aware about acceptability } \\
\text { rriteria }\end{array}$ & 4 & 40 \\
\hline 3. & $\begin{array}{l}\text { Satisfactory manoeuvre } \\
\text { demonstration to patients }\end{array}$ & 7 & 70 \\
\hline 4. & $\begin{array}{l}\text { Aware about maximum } \\
\text { number of attempts }\end{array}$ & 5 & 50 \\
\hline 5. & $\begin{array}{l}\text { Knowledge about } \\
\text { infection control } \\
\text { measures }\end{array}$ & 3 & 30 \\
\hline 6. & $\begin{array}{l}\text { Knowing } \\
\text { contraindications of } \\
\text { spirometry }\end{array}$ & 20 \\
\hline
\end{tabular}

Table 4: Most Common Error Performed by Technician

\section{RESULTS}

A total of 207 patients with spirogram enrolled for study between July 2015 and Sep 2015. The mean age and BMI of study patients are 43.7 yrs. and 22.4, respectively. The spirogram from 207 patients interpreted as obstructive, restrictive and normal in 52.65, 21.73 and 25.60 percentage respectively (Table 1 ).

These studies show that only $14 \%$ spirograms were acceptable. The spirograms were reproducible only in 51.69\%.

The reversibility testing was performed in only $16.90 \%$ and so only $32.11 \%$ of obstructive spirograms underwent reversibility testing. The average number of attempts taken by patients were three and when we look on number of acceptable manoeuvres that came out as less than one; at least three acceptable manoeuvres were found only in 18.37 percentage.

If we look on reason for unacceptable spirograms, almost 93.26\% patients have some error in flow volume curve and more than half of spirograms were not reproducible. The most common error found in flow volume curve was blunt peak $(50.96 \%)$ followed by notch in early part (30.76), variable effort (30.76), delayed peak (16.34), false start present (11.53) (Table 3).

Focussing on awareness about spirometry among technician shows that not all technician take weight and height accurately by scale ( 9 out of 10). Many technicians were not aware about acceptability criteria, number of attempts or indication of reversibility (Table 4).

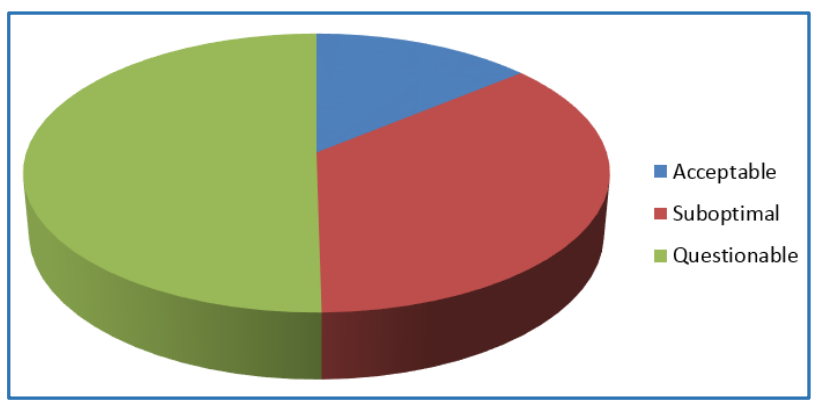

Fig. 1: Quality of Spirometry

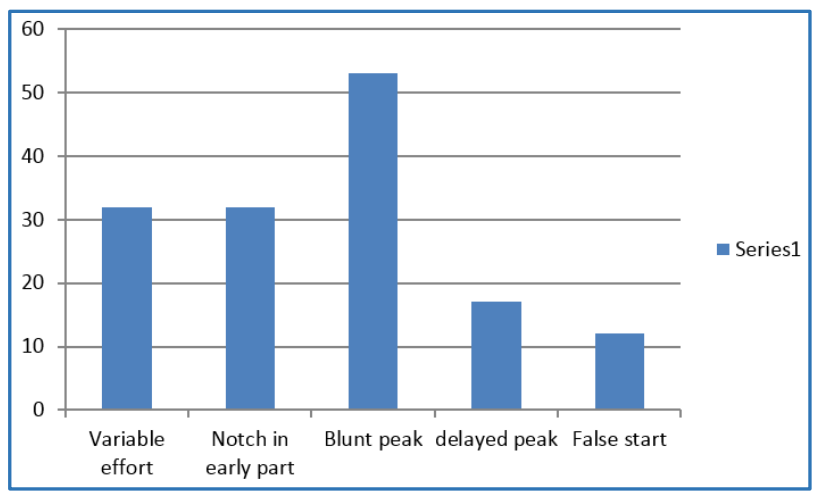

Fig. 2: Type of Flow Volume Curve Abnormality

\section{DISCUSSION}

This study shows that majority of spirometry performed were unacceptable. The flow volume curve was acceptable in only $14 \%$. At least three acceptable manoeuvres were performed only in 18.37 percent and only half of spirogram fulfil criteria of reversibility. We have not found any Indian study regarding quality of spirometry. The most common error found in flow volume curve was blunt peak followed by notch in early part, variable effort, delayed peak, false start present. Our finding is similar to 1999 Eaton et al(6) study of quality of spirometry in 30 randomly selected primary care and they found that only $33.1 \%$ and $12.5 \%$ of patient tests in groups with and without training respectively achieved the required minimum of two acceptable blows. Tuomisto et al(7) retrospectively assessed the quality of spirometry tracings enclosed with referral letters from Finnish GPs. They concluded that the majority of 
spirometry tracings were of a high standard. Conversely, Den Otter et al(8) demonstrated that primary care spirometry does not always meet good quality standards.

It was observed that frequency of reversibility testing performed in only one-third of obstructive spirogram. This shows the poor awareness among physician as well as technician about its importance in diagnosis of respiratory diseases.

This study also focus on awareness about spirometry among technicians, which shows that not all technicians take weight and height accurately by scale ( 8 out of 10 ). Two technicians found that they take weight and height approximately just on the basis of look and built of patient.

When asked about different technical aspects many technicians were not aware about acceptability criteria, number of attempts or indication of reversibility.

Spirometry is effort-dependent procedure and the role of the person doing the test as guide for the patient cannot be overestimated. Training and regular practice is vital. Likewise, the results of spirometry testing need to be properly interpreted in the light of the clinical details ideally at the time of testing. However, it appears from the available data that the proportion of unacceptable tests performed in primary care is likely to be too high.

\section{Limitation of Study}

Spirometry result depend upon several factors like training of technician, type and condition of spirometer, disease severity and many other factors which are not considered in the study. This study did not include clinical details of patients as well as type and duration of training received by technician is not clear.

\section{REFERENCES}

1. Miller MR, Hankinson J, Brusasco V, et al. Standardisation of spirometry. Eur Resp J 2005;26(2):319-38.

2. Gupta D, Agarwal R, Aggarwal AN, et al. Guidelines for diagnosis and management of chronic obstructive pulmonary disease: joint ICS/NCCP (I) recommendations. Lung India 2013;30(3):228-67.

3. Enright P. The use and abuse of office spirometry. Prim Care Resp J 2008;17(4):238-42.

4. Yawn BP, Enright PL, Lemanske RF, et al. Spirometry can be done in family physicians' offices and alters clinical decisions in management of asthma and COPD. Chest 2007;132(4):1162-8.

5. Stanley AJ, Hasan I, Crockett AJ, et al. Validation of the COPD diagnostic questionnaire in an Australian general practice cohort: a cross-sectional study. Prim Care Respir J 2014;23(1):92-7.

6. Eaton T, Withy S, Garrett JE, et al. Spirometry in primary care practice: the importance of quality assurance and the spirometry workshops. Chest 1999;116(2):416-23.

7. Tuomisto L, Jarvinen V, Laitinen J, et al. Asthma programme in Finland: the quality of primary care spirometry is good. Prim Care Resp J 2008;17(4):226-31.

8. Den Otter JJ, Knitel M, Akkermans RP, et al. Spirometry in general practice: the performance of practice assistants scored by lung function technicians. Br J Gen Pract 1997;47(414):41-2. 